\title{
Strategy Analysis of Physical Exercise Promoting College Students' Physical Health under the Background of Healthy China
}

\author{
Zili Niu \\ Sports Institute of Wuhan Business University \\ Wuhan, Hubei, 430079
}

\begin{abstract}
This paper, regarding college students' physical exercise as the research object, studies the effect of physical exercise on college students' physical health, current status and dilemma of its carrying out in colleges and universities with the method of literature to seek the implementation strategy to promote college students' physical health and make theoretical exploration and practical innovation on this basis. They should take effective methods to guide college students to participate in physical exercise and promote their physical health even the strategy of healthy China.
\end{abstract}

Keywords—healthy China; physical training; college students; physical health

In the report of the 19th NCCPC (on October 18, 2017), President Xi Jinping pointed out the implementation of healthy China. We should promote the national fitness strategy and offer overall health service for our people. While college students are regarded as the attention of this strategy, so their physical and mental health is not only related with their own growth but also the development of the whole nation. The National Fitness Program Outline issued in 1995 pointed out that "We should focus on teenagers and children and motivate the whole society to care about their health, let them have life-long sports education and train the awareness, skills and habits of physical exercise [1]". However, current college students in our country have worse physical qualities. Therefore, it has become the urgent problem to improve their physical health level.

\section{THE EFFECT OF PHYSICAL EXERCISE ON COLLEGE STUDENTS' PHYSICAL HEALTH}

In 2016, Plan of "Healthy China 2030" was issued by the CPC central committee and the state council, which pointed out that "We should carry out the promotion plan for teenagers' sports activities, train their sports hobbies to basically achieve that they can skillfully master more than one physical skill and ensure them have more than one hour doing physical activities [2]". Health is placed with great priority of development in this outline. The CPC central committee and the state council require teenagers to skillfully master one kind of activity skills and make out the minimum standard of everyday sports activities with the method of issuing documents. Physical exercise is very crucial to teenagers' physical health.

This paper is the staged achievements of scientific research program in Wuhan Business University hosted by the author, "Research on the Current Status and Solution of College Students'Physical Exercise under the Background of Healthy China - Taking the example of Wuhan Business University" (Grant No. 2018KY002).

\section{A. Impacts on body shape}

Physical exercise can promote the metabolism of bones. And bones become stronger than before. The ability of bones on resisting bent and broken also increases, augmenting the muscle volume. The muscles of people who exercise regularly are significantly larger than those of ordinary people.

\section{B. Effects on physiological functions}

Physical exercise is good for the development of the nervous system, functions of the nervous system and he heart and blood vessels in the circulatory system. In addition, it can increase the strength of respiratory muscles in respiratory system and lung capacity. What's more, it can enhance the function of digestive system and improve the digestion and absorption capacity.

\section{Impacts on physical quality}

Physical exercise will enhance people's strength, speed, endurance, flexibility and sensitivity, which are the external performances of a person's physical strength. Various physical quality levels can be enhanced from all the aspects through correct methods and proper exercise.

\section{Effects on psychological quality}

Strengthening physical exercise can not only timely throw badly and negative mood out to help the development of physical and mental health, but also contributes to the training and formation of strong will. In the process of exercise, they are supposed to constantly overcome all the difficulties and perfect will quality will be gradually formed in such process.

\section{E. Impact on social Adaptability}

Physical exercise can promote the formation of cooperative awareness and ability, conducive to the cultivation of a good sense of competition, perfect interpersonal skills and modern lifestyle as well as the improvement of people's adaptability to the environment and society.

\section{CURRENT STATUS OF PHYSICAL EXERCISE IN COLLEGES AND UNIVERSITIES}

All the districts and departments have constantly issued policies and measures in recent years to vigorously carry out sunshine sports activities and made positive progress. Its result is expressed in the national physical fitness monitoring bulletin and current status survey of college students' physical exercise. Chinese college students’ physical development levels in 2014, 
namely, the height, weight and chest circumference, have continually improved when compared with that one in 2010, according to the national physical fitness monitor bulletin of 2014. Physical qualities of primary and middle school students continue to develop with a steady and positive trend. But school physical education is still rather poor in the whole education course. Students' physical health level is still the obvious disadvantage of students' qualities ${ }^{[3]}$. At present, college students' physical health condition is still worrying, which keeps declining. Still, there are a number of younger students with weak eyesight. And more students in every age tend to be fat. In the investigation of current status of college students' physical exercise in Shandong province, Cao Yuanqi (2016) found that the first three things that students selected to spend time on are surfing the Internet through computers, professional learning and playing mobile phones. And physical exercise ranked the fifth. Its average selection coefficient is only 0.64 . While in the survey of college students' extracurricular physical exercise in Liaoning province, Li Zhuo (2017) found that the first three ones are listening to music, surfing the Internet and watching videos, respectively accounting for $63 \%, 58 \%$ and $47.3 \%$. There are $42.9 \%$ of the students choosing physical exercise. And he found in the survey of students' practical exercise behavior that only $29.6 \%$ of the students were in the behavior stage and maintaining stage of exercise, and the others seldom even never exercise. It can be seen that the result of physical exercise in colleges is not ideal from continuous declining of college students' physical qualities, increasing of obesity and their emphasis level on physical exercise.

\section{COLLEGES' TROUBLE IN CARRYING OUT PHYSICAL EXERCISE}

China has always attached great importance to college students' physical health, and teenagers have been the focus all the time from National Fitness Program Outline in 1995 to Plan of "Healthy China 2030" in 2016. Colleges are also making efforts to carry out various sports activities and issue corresponding documents to urge students to exercise. But college students' physical quality is still declining and the obesity rate is continually rising. There exist some challenges of physical exercise carried out in colleges and universities.

\section{A. Colleges lack effective supervision mechanism}

Even though some colleges give students time for extracurricular physical exercise, this kind of exercise is just a formality and students can only guarantee their presence for lacking of corresponding supervision measures. Colleges fail to make requirements with the pattern and level of exercise, so the quality of physical exercise cannot be ensured.

\section{B. Colleges lack sports ground}

College students need to rely on the stadium for physical exercise. So, it is the premise for their physical exercise that there are perfect and enough sports equipment and facilities. Sports ground, facility types and size of colleges will affect the mode and activity mode of students' participation in physical exercise. Currently, lots of colleges lack enough sports facilities and cannot meet the demands of students' physical exercise, which having bad effects on their physical exercise.

\section{College students don't have enough cognition with sports exercise}

College students have much disposable time, but most of them will choose to spend time surfing the Internet, playing games and doing part-time jobs, not doing physical exercise. Internet has great influences on present college students. They can know the outside world without leaving home. Students can even spend the whole day on micro-blog, virtual zone and games in their dormitories. Their understanding with physical exercise needs to be improved.

\section{College sports culture construction is relatively poor}

The number of students taking part in every activity is not ideal, although colleges regularly hold sports competition and activities. And there are less people that will be influenced. Besides, colleges should strengthen the propaganda on the outlook of sports and health.

\section{E. College students lack systematic exercise guidance}

Most college students exercise blindly and unscientifically. They even don't know which kind of exercise fits themselves. A platform responsible by professional teaching staff will timely examine students' exercise and provide corresponding guidance, and students will be more willing to exercise.

\section{F. Families lack enough emphasis on physical exercise}

Many families attach more importance to scores than physical quality development, not knowing a healthy body is the essential. What's more, some items require to purchase equipment and facilities in physical exercise. Students will be discouraged if their parents don't give support under the circumstance of money permitting.

\section{IMPLEMENTING STRATEGIES OF PHYSICAL EXERCISE TO PROMOTE COLLEGE STUDENTS’ PHYSICAL HEALTH}

\section{A. Improve the supervision and management mechanism}

The participation of college students requires sound supervision and management system to timely track and monitor students. Related management system supervises students to have daily physical exercise and includes physical exercise into students' related assessment. And it is regarded as the reference basis of excellence. Such sound supervision and management mechanism can supervise students to have extracurricular physical exercise.

\section{B. Improve the equipment and facilities of physical exercise}

Colleges should strengthen the equipment construction of the stadium. On the one hand, increase sufficient facilities to improve exercise environment and provide good physical exercise conditions for students; On the other hand, some new and interesting physical facilities can be properly added, such as digital tennis, network fitness bicycle. They can make college students' physical exercise full of fun and not limited by time, climate and ground, which has positive effect on their participation in physical exercise.

\section{Build a guidance platform for sports training}

College students' physical exercise need scientific and professional guidance, which needs to build a guidance platform for physical exercise to provide services for college 
students, help students learn systematic sports skills and theories and further select suitable sports mode. The platform can gather the collective wisdom of related professional teachers to provide intellectual support and training guarantee for students through the consultation, measurement and evaluation, sports prescription and training guidance.

\section{Strengthen the construction of college sports culture}

College sports culture is a significant part of campus culture. Strengthening the construction of campus sports culture is conducive to building their healthy bodies and complete personalities, cultivating their lifelong sports awareness and creating a good campus culture atmosphere. Regular fun sports games, sports culture festivals and other diversified sports competitions are to mobilize most college students' enthusiasm about exercise and promote the cultivation of good sports habits.

\section{E. Guide students to build correct outlook of health}

College students' lack of sports cognition may cause the problem in physical exercise. And the specific cognition of common students is one of the most direct reasons. College students have plenty of spare time to guarantee the participation in physical exercise. Many students don't select physical exercise, indicating that they lack correct sports outlook, cognition and emphasis. Colleges should deliver the physical atmosphere of class and school to students' daily life, in order to make students unconsciously realize the importance of health, positively do physical exercise and form positive and healthy life mode.

\section{F. Give play to the role of the family on physical exercise}

Family education lays the solid foundation for other education. Parents are the first teachers of children, and family education will directly have an influence on the life of teenagers ${ }^{[6]}$. Parents' traditional concepts, that is, students should attach more importance to study rather than physical exercise, to intelligence development rather than physical health should be guided. Zhang Boling thinks that "Education

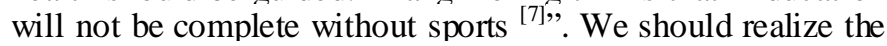
irreplaceable role of sports in quality education and its effect on the promotion of teenagers' physical quality and intelligence. Parents should not only supervise students to timely exercise and strengthen body quality, but also offer students appropriate funds for sports consumption, such as purchasing sports goods or service to enhance exercise effect.

\section{CONCLUSION}

College students, as a part of the youth, are the attention of national fitness plan. Only one department cannot independently promote college students' physical health, and it needs multiple cooperation of the government, school, society, family and students. The related departments of government should give countermeasures and deepen the supervision; society should establish correct outlook of education and talents and make overall assessment with school, teachers and students, not just staring at the score, enrollment rate and employment rate. Colleges are supposed to improve the management mechanism of students' physical exercise, strengthen campus sports culture construction, improve sports equipment and facilities, build physical exercise platform and guide students to set up correct healthy concept. Parents should have correct outlook on health and talents. Multiple cooperation can eventually advance their cognition about sports and health knowledge, promote their health behavior motivation and help them form good healthy sports behavior [8]

\section{REFERENCES}

[1] State Council: Nationwide fitness program outline [EB/OL].http://www.scio.gov.cn/xwfbh/xwbfbh/wqfbh/2015/33862/xg z c33869/Document/1458253/1458253.htm.

[2] The CPC central committee and the state council: Plan of "Healthy China 2030"

[EB/OL].http://www.gov.cn/zhengce/2016-10/25/content_5124174.htm

[3] Opinions of the general office of State Council on strengthening college sports and promoting overall development of students' physical and mental health[R].2016.

[4] Bulletin on national physical fitness [EB/OL].http://www.gov.cn/guoqing/2016-05/13/content_5073091.htm

[5] Cai Hao. Investigation on college students' sports cognition and behavior in Shanghai[J]. Sports Culture Guide, 2007(9):72-74.

[6] He Jing zhou and Zhu Wei. Investigation and research on the current status of middle school students participating in physical exercise in Shaanxi province[J]. Journal of Xi'an University of Physical Education, 2017, 34(4):464-467).

[7] Zhang Boling. A person who does not know sports should not be a principal [N]. China Education Journal, 2014-07-31( 3).

[8] Huang Liuqian and Huang Xiang. Research on the factors influencing health sports behavior of college students in Guangxi province[J]. Journal of Guangzhou Institute of Physical Education, 2017, 37(1): 42-47. 